US Army Corps

of Engineers ${ }_{\circledast}$

Engineer Research and

Development Center

Navigation Systems Research Program

\title{
Towing Vessel Delays and Barge Lane Navigability along the Houston Ship Channel, Texas
}

Kenneth N. Mitchell, Patricia K. DiJoseph, Brandan M. Scully,

January 2020 and Marin M. Kress

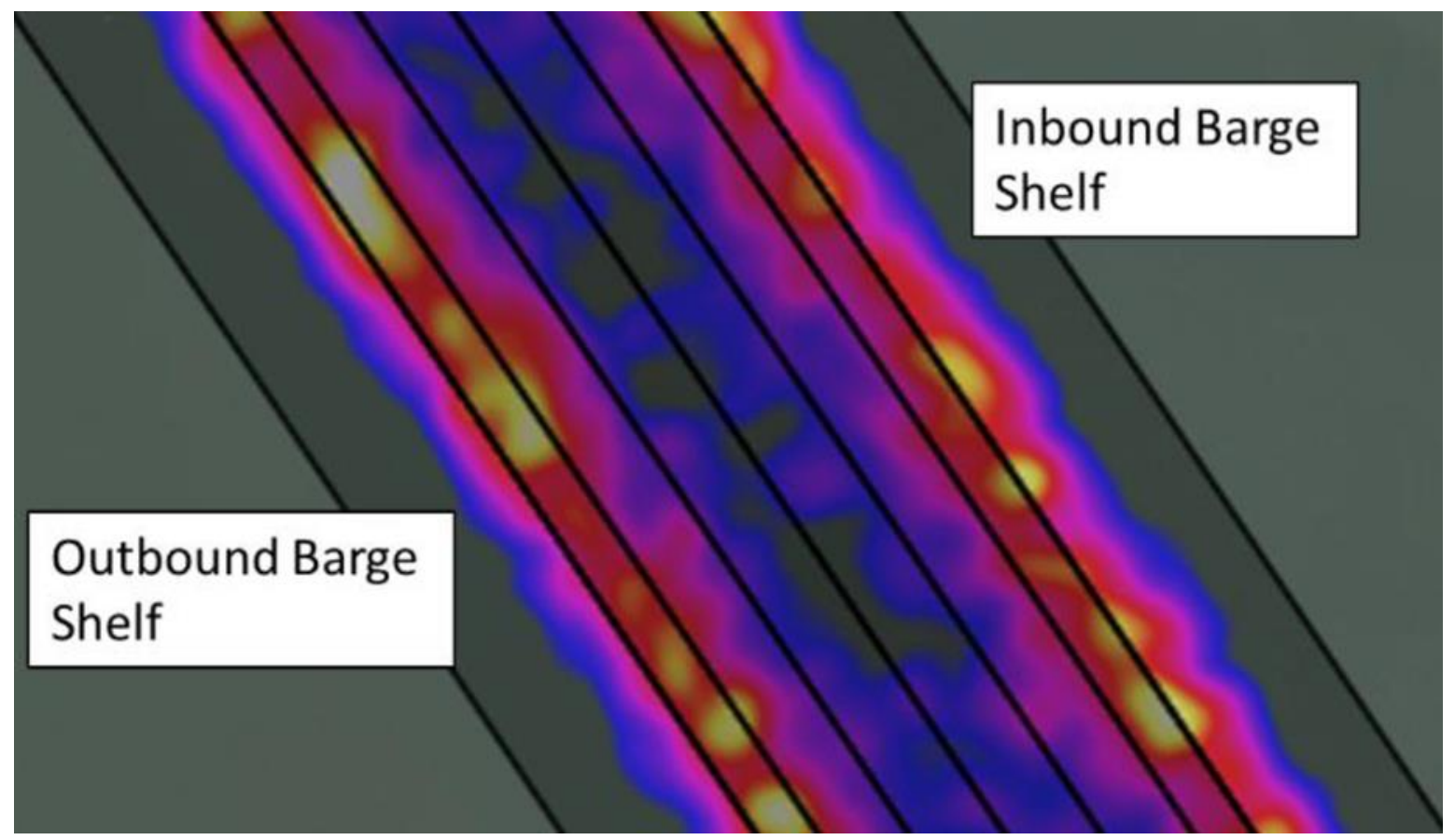


The U.S. Army Engineer Research and Development Center (ERDC) solves the nation's toughest engineering and environmental challenges. ERDC develops innovative solutions in civil and military engineering, geospatial sciences, water resources, and environmental sciences for the Army, the Department of Defense, civilian agencies, and our nation's public good. Find out more at www.erdc.usace.army.mil.

To search for other technical reports published by ERDC, visit the ERDC online library at http://acwc.sdp.sirsi.net/client/default. 


\section{Towing Vessel Delays and Barge Lane Navigability along the Houston Ship Channel, Texas}

Kenneth N. Mitchell, Patricia K. DiJoseph, Brandan M. Scully, and Marin M. Kress

Coastal and Hydraulics Laboratory

U.S. Army Engineer Research and Development Center

3909 halls Ferry Road

Vicksburg, MS 39180-6199

Final report

Approved for public release; distribution is unlimited.

Prepared for U.S. Army Corps of Engineers, Galveston District

2000 Fort Point Rd.

Galveston, TX 77550

Under Project 468419, "Port Performance and Resiliency" and Dredging Operations Technical Support (DOTS) 


\section{Abstract}

This project used historic vessel position reports to analyze barge lane traffic navigability and towing vessel traffic interaction with deep draft ("bluewater") vessels in the Houston Ship Channel, Texas, during September and December 2015. Vessel position reports were collected through the U.S. Coast Guard Nationwide Automatic Identification System (AIS) and accessed through the U.S. Army Corps of Engineers AIS Analysis Package software. The motivation for this study was a request from the Galveston District for assistance as part of the Houston Ship Channel Expansion Channel Improvement Project. Results indicate that, generally, towing vessels confine themselves to the designated barge shelves on the outer edges of the main channel approximately $65 \%$ of the time and venture into the main (center) portion of the deep-draft channel approximately $35 \%$ of the time. This study also explored the relationship between meeting events (where a bluewater vessel is meeting a towing vessel moving in the opposite direction) and the linear consistency of towing vessel tracks within the barge lanes along straight segments of the Houston Ship Channel. Preliminary results suggest that encounter events do influence towing vessel behavior, as measured through vessel track linearity.

DISCLAIMER: The contents of this report are not to be used for advertising, publication, or promotional purposes. Citation of trade names does not constitute an official endorsement or approval of the use of such commercial products. All product names and trademarks cited are the property of their respective owners. The findings of this report are not to be construed as an official Department of the Army position unless so designated by other authorized documents. 


\section{Contents}

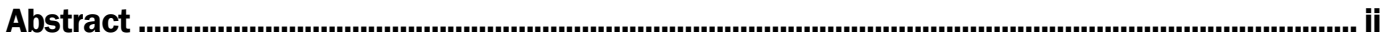

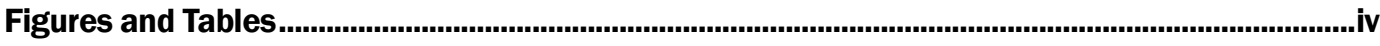

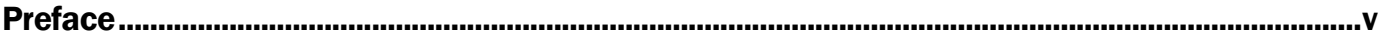

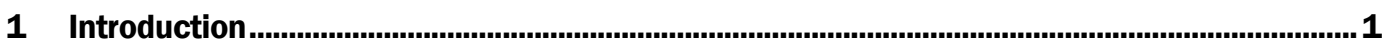

1.1 Background - Initial request from Galveston District (SWG) ................................. 1

1.2 Objective - Respond to SWG request ........................................................... 1

1.3 Approach - Identify study area and timespan ................................................... 2

2 Methods ....................................................................................................................................... 4

2.1 Automatic Identification System (AIS) data acquisition ........................................ 4

2.2 Evaluation of barge shelf utilization ..................................................................... 4

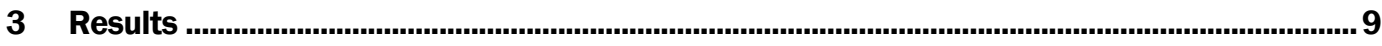

3.1 HSC transits by direction and classification of vessel encounter events ................... 9

3.2 Relative linearity of towing vessel tracks as a function of bluewater vessel

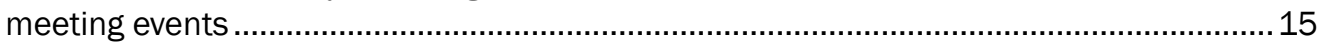

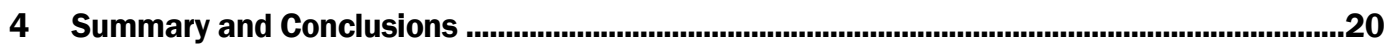

References .................................................................................................................................................21

Unit Conversion Factors .........................................................................................................22

\section{Report Documentation Page}




\section{Figures and Tables}

\section{Figures}

Figure 1. Overview of study area, HSC, divided into three Segments (S1, S2, S3). Dark blue lines show USACE-maintained navigation channels in the area

Figure 2. Spatial delineations used within AISAP for HSC towing vessel analysis (looking north)

Figure 3. Heat map traffic visual for representative portion of the HSC-S2, with eight sections of channel (two barge shelves, two side slopes, and four channel quarters A-D) labeled accordingly. Heatmap color scale for the relative number of position reports ranges from blue-purple (low) to pink (medium) to yellow-white (high)

Figure 4. AISAP AOI (color-shaded boxes in $4 a, 4 b$, and $4 c$ indicated by white arrows) used to delineate the ends of straight-line segments of HSC for vessel meeting and overtaking analysis.

Figure 5. Example of AISAP travel time output file. ………............................................................10

Figure 6. Visualization of using respective entry/exit time stamps to infer overtaking events.

Figure 7. Visualization of using respective entry/exit time stamps to infer meeting events

Figure 8. Inbound towing vessel travel times by number of meeting/overtaking events HSC-S2 - December 2015.

Figure 9. Outbound towing vessel travel times by number of meeting/overtaking events HSC-S2-December 2015

Figure 10. Comparison of towing vessel tracks with "high" $\mathrm{R}^{2}$ value (green line) and relatively “low" $R^{2}$ value (purple line).

Figure 11. Comparison of towing vessel tracks with relatively high $R^{2}$ (panel A) and low $R^{2}$ (panel B) coefficients within a southern portion of HSC-S2.

Figure 12. Comparison of towing vessel tracks with relatively high $R^{2}$ (panel $A$ ) and low $R^{2}$ (panel B) coefficients within a northern portion of HSC-S2.

Figure 13. Trends in towing vessel track $R^{2}$ values as bluewater vessel encounters increase - HSC-S2- December 2015

Figure 14. Median $\mathrm{R}^{2}$ values for towing vessel tracks as bluewater vessel encounters increase, HSC-S2, December 2015.

\section{Tables}

Table 1. Results of AIS archival vessel position reports analysis for barge shelves and HSC

Table 2. Distribution of towing vessel AIS positions reports within cross section of HSC-S2. ............. 7

Table 3. Summary of towing vessels meeting or being overtaken by other vessels (oceangoing or towing), September 2015. 


\section{Preface}

This study was conducted for the U.S. Army Corps of Engineers (USACE) Galveston District, under Project 468419, "Port Performance and Resiliency." Funding was provided through the USACE Dredging Operations Technical Support (DOTS) program. The DOTS Program Manager was Dr. Burton Suedel, U.S. Army Engineer Research and Development Center, Environmental Laboratory (ERDC-EL). Funding to publish this work was provided by the USACE Navigation Systems (NavSys) Research Program. The NavSys Program Manager was Mr. Charles E. Wiggins, ERDC Coastal and Hydraulics Laboratory (ERDC-CHL), and ERDC Technical Director for Navigation.

The work was performed by the Coastal Engineering Branch of the Navigation Division and the Navigation Branch of the Navigation Division, ERDC-CHL. At the time of publication of this report, Ms. Lauren Dunkin was Chief of the Coastal Engineering Branch, and Mr. Benjamin Burnham was Chief of the Navigation Branch. Dr. Jacqueline S. Pettway was Chief of the Navigation Division. The Deputy Director of ERDC-CHL was Mr. Jeffrey R. Eckstein, and the Director was Dr. Ty V. Wamsley.

Valuable reviews of the draft version of this technical report were provided by Ms. Morgan Johnston and Mr. Brian Tetreault, ERDC-CHL.

COL Teresa A. Schlosser was the Commander of ERDC, and the Director was Dr. David W. Pittman. 


\section{Introduction}

\subsection{Background - Initial request from Galveston District (SWG)}

This report summarizes activities undertaken by the U.S. Army Engineer Research and Development Center, Coastal and Hydraulics Laboratory (ERDC-CHL), to support the U.S. Army Corps of Engineers (USACE) Galveston District (SWG) concerning questions of a possible water surface drawdown effect (where available channel depth is temporarily reduced), and subsequent hazardous navigable conditions experienced by towing vessels transiting the barge lanes on either side of the Houston Ship Channel (HSC).

\subsection{Objective - Respond to SWG request}

The objective of this work was to respond to the request for assistance from SWG by producing an initial reply and supporting documentation within a relatively short time period. Through the ERDC Dredging Operations Technical Support (DOTS) program, districts can request assistance on small projects achievable within a 2-week window by ERDC researchers, with labor funding provided by the DOTS program. The original DOTS request submission from January 2018 reads as follows:

"Houston Ship Channel Expansion Channel Improvement Project (HSCECIP) requests ERDC assistance to identify and quantify barge and deep draft vessel delays in Galveston Bay associated with the existing barge lane channel design. This includes but is not limited to (1) identification of channel/traffic conditions which force barge traffic from the barge lane into the main channel, (2) historical frequency and duration of item 1, (3) barge and deep draft vessel speed reduction associated with item 1, and (4) estimation of future impact of item 1 given vessel fleet forecast of HSCECIP. This will involve in-depth analysis of Automatic Identification System (AIS) data from Houston Ship Channel as well as coordination with HSC-ECIP economics team and the Deep Draft Navigation Planning Center of Expertise [DDNPCX]. This request is meant to fund the development of a scope, schedule, and cost estimate for the above items. This will likely include at least 2 meetings with the Project Delivery Team and DDNPCX to coordinate study needs and potential path forward." 


\subsection{Approach - Identify study area and timespan}

The first conference call to discuss this submittal was held on 7 February 2018, with HSC-ECIP representatives indicating that rather than focus on a detailed scoping effort, the DOTS funding should be used to process samples of historic vessel position reports (hereafter, "AIS data") towards answering the four questions posed in the request to the extent possible. A follow-up call was held on 27 April 2018 during which HSC-ECIP representatives posed more focused questions concerning the extent to which towing vessels transiting the HSC utilize the provided barge lanes (as opposed to transiting within the deep-draft channel).

Figure 1 shows the study area centered on the HSC running approximately north-south within Galveston Bay, Texas. To facilitate a portion of the analysis that sought to evaluate the linearity of towing vessel tracks relative to the number of associated meeting and overtaking events experienced (i.e., any type of vessel adjacency events), the bay portion of the HSC was divided into three straight-line segments, indicated by Segments S1, S2, and $\mathrm{S} 3$ in Figure 1. This segmentation was determined by intersections between the HSC and major side channels. Segment 1 is approximately 9 miles long and runs from the intersection with the Gulf Intracoastal Waterway northward to the intersection with the side channel to Double Bayou (i.e., the channel to Liberty). Segment 2 is approximately 7.75 miles long and runs from the intersection with the side channel to Double Bayou northwards to the intersection with the Bayport entrance channel. Segment 3 is approximately 5 miles long and runs from the intersection with the Bayport entrance channel northwards to the intersection with the Barbours Cut channel. Further technical details are included in Chapter 2: Methods. 
Figure 1. Overview of study area, HSC, divided into three Segments (S1, S2, S3). Dark blue lines show USACE-maintained navigation channels in the area.

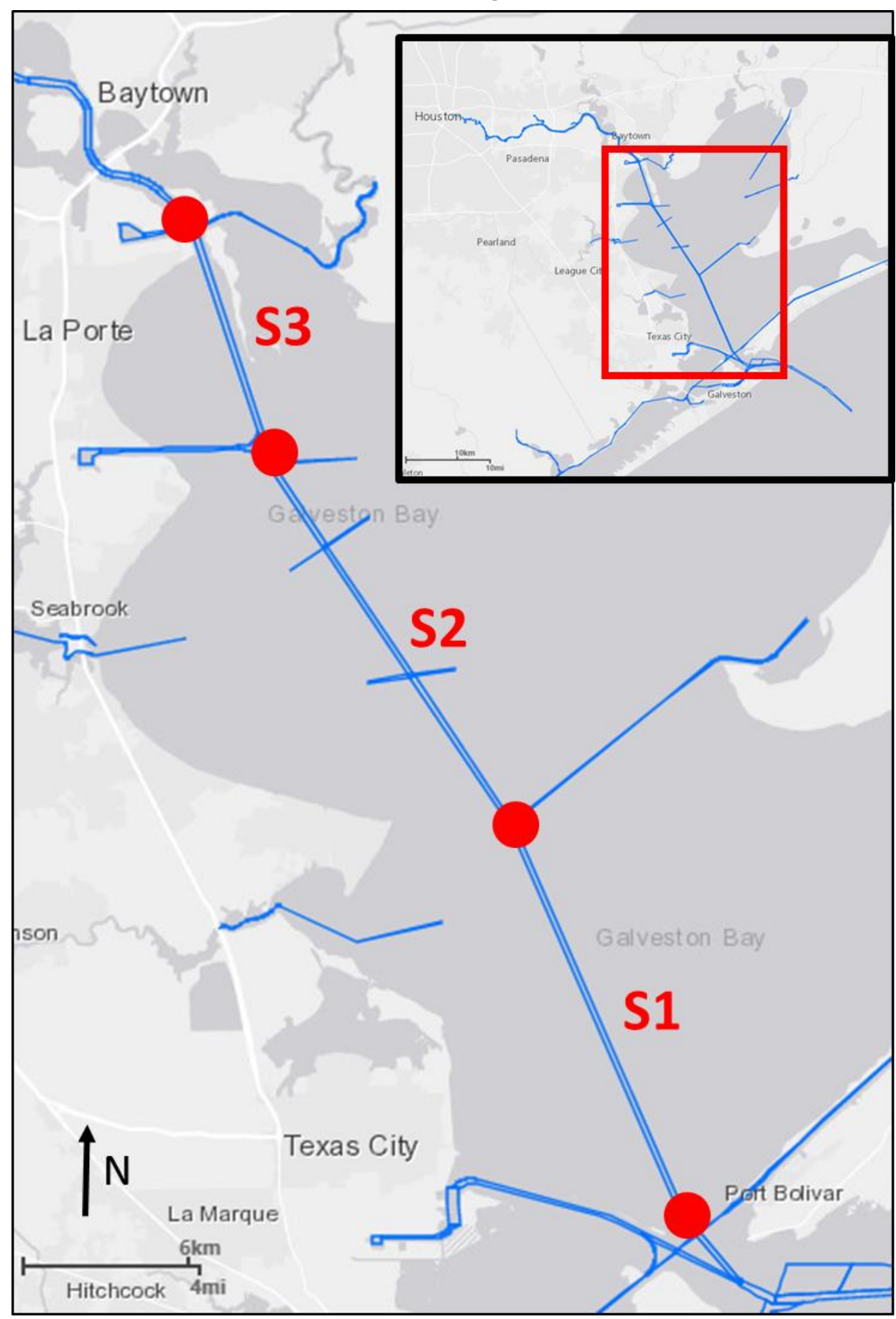




\section{Methods}

\subsection{Automatic Identification System (AIS) data acquisition}

To support this study effort, the USACE-ERDC Automatic Identification System Analysis Package (AISAP: https://ais-portal.usace.army.mil) was used to download 1-month samples of historic vessel position records from the U.S. Coast Guard Nationwide AIS archive (USACE-ERDC 2018). The AIS data contain time-stamped vessel position reports for all commercial vessels transiting within the HSC, as well as vessel identifying information, speeds, headings, and ship types and dimensions. The position reports were sampled at the 6-second time period between broadcasts, which is generally the highest possible sampling rate, thereby providing a high degree of granularity for subsequent spatio-temporal processing (U.S. Coast Guard 2018).

\subsection{Evaluation of barge shelf utilization}

Per questions posed by the SWG team during the two conference calls held to discuss this effort, an evaluation of barge shelf utilization rates was conducted using AIS data obtained from September 2015 and December 2015, chosen to provide representative coverage of seasonally varying navigable conditions. Data from 2015 was used because it was already available and ready for analysis. SWG provided shapefile geometries for the designated barge shelves on either side of the HSC. The USACE Navigation Channel Framework was used to provide geospatial coordinates for the HSC itself. In this initial spatial analysis, the designated HSC footprint included the channel side slopes that run between the deep-draft channel and the adjacent barge shelves. Table 1 shows the results of the AIS archival towing vessel position reports for September and December of 2015 along Segment 2 ("S2" in Figure 1) of the HSC. Segment S2 was chosen for initial analysis because of its location in the middle of the study area. 
Table 1. Results of AIS archival vessel position reports analysis for barge shelves and HSC.

\begin{tabular}{|l|c|c|c|c|}
\hline & \multicolumn{2}{|c|}{ September 2015 } & \multicolumn{2}{c|}{ December 2015 } \\
\cline { 2 - 5 } & $\begin{array}{c}\text { Number of Towing } \\
\text { Vessel Position } \\
\text { Reports }\end{array}$ & $\begin{array}{c}\text { Number of Unique } \\
\text { Towing Vessels }\end{array}$ & $\begin{array}{c}\text { Number of Towing } \\
\text { Vessel Position } \\
\text { Reports }\end{array}$ & $\begin{array}{c}\text { Number of Unique } \\
\text { Towing Vessels }\end{array}$ \\
\hline $\begin{array}{l}\text { HSC } \\
\text { (including side slopes) }\end{array}$ & 420,543 & 364 & 414,503 & 339 \\
\hline Outbound barge lane & 90,840 & 294 & 84,828 & 280 \\
\hline Inbound barge lane & 96,112 & 288 & 86,635 & 275 \\
\hline
\end{tabular}

In percentage terms, the barge lanes are shown to contain $30.77 \%$ of towing vessel position reports in September and $29.26 \%$ of towing vessel position reports in December. Since these numbers straddle the $30 \%$ benchmark, based on these 2 months of observed data, it can be credibly stated that the towing vessels utilize the main ship channel (including side slopes) approximately $70 \%$ of time while occupying the designated barge lanes approximately $30 \%$ of the time.

A further spatial analysis was conducted to see where exactly within the HSC cross section the towing vessels tend to track. The HSC cross section between the two barge shelves was divided into six portions representing the two channel side slopes as well as the four channel quarters, labeled A-D as shown in Figure 2.

Figure 2. Spatial delineations used within AISAP for HSC towing vessel analysis (looking north).

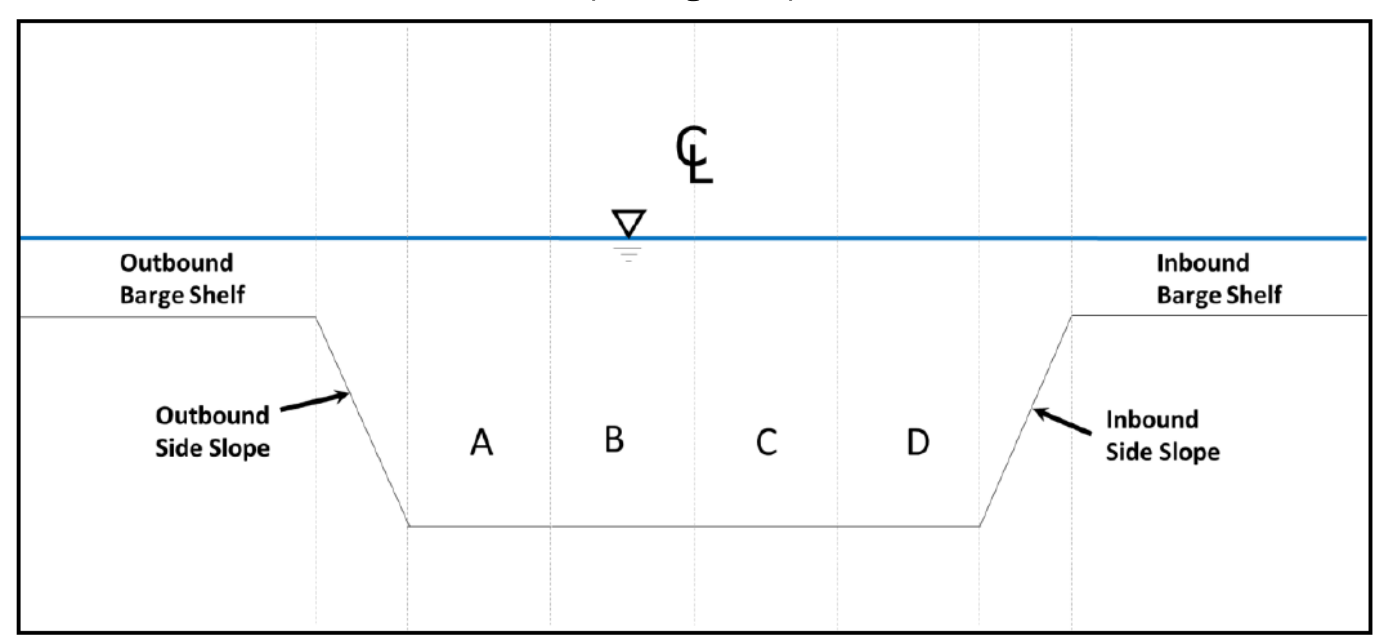


The position reports for towing vessels transiting the HSC during the months of September and December 2015 were again analyzed relative to the respective footprints indicated in Figure 2 and applied to Segment 2 ("S2" in Figure 1). Figure 3 provides a map visualization of the relative traffic density patterns across the eight segments delineated in Figure 2, for a representative portion of Segment S2. The main portion of Figure 3 shows the general consistency of traffic density along the length of the different Segment S2 channel segments.

Figure 3. Heat map traffic visual for representative portion of the HSC-S2, with eight sections of channel (two barge shelves, two side slopes, and four channel quarters A-D) labeled accordingly. Heatmap color scale for the relative number of position reports ranges from bluepurple (low) to pink (medium) to yellow-white (high).

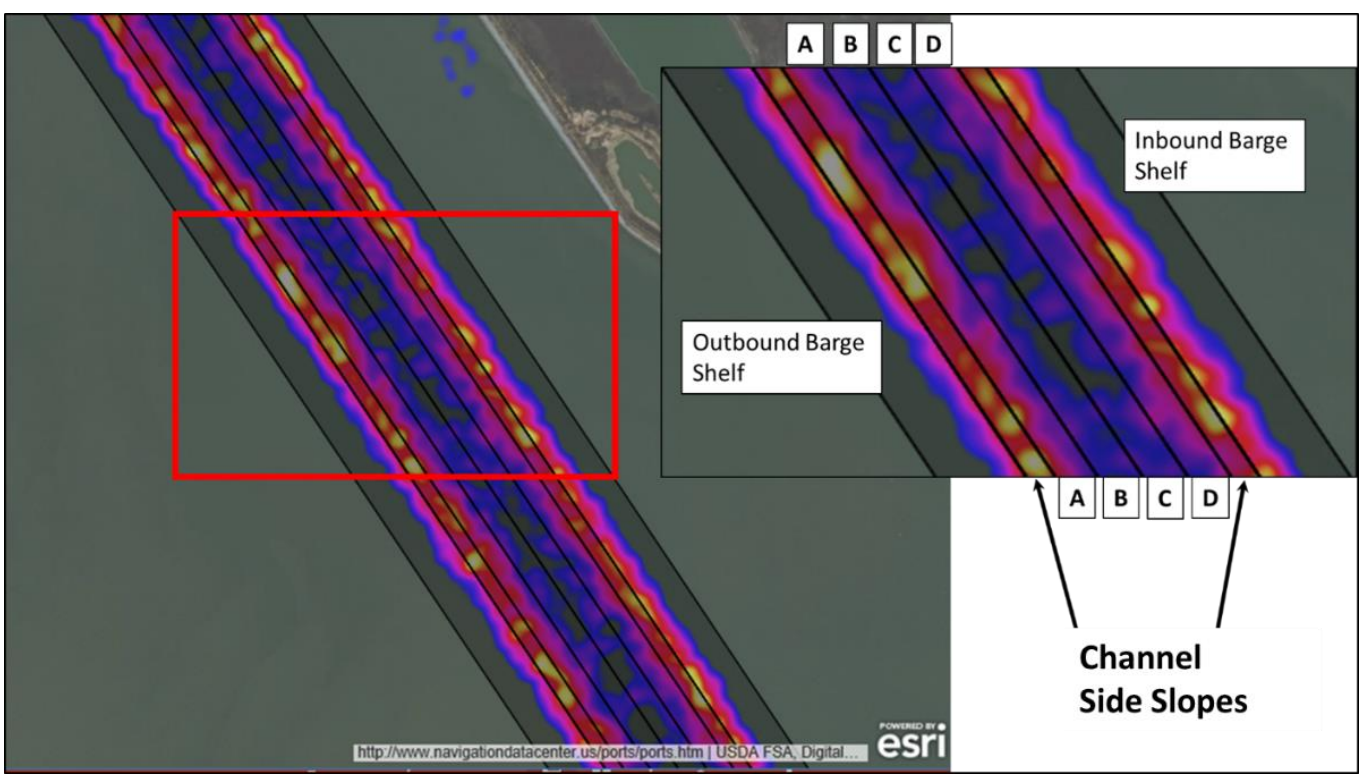

For the outbound (southward) and inbound (northward) transit directions, towing vessels are observed to concentrate within the channel side slope portions of the overall cross section, though clearly there are vessel position reports observed across all portions of the channel. To provide actual observed quantities of towing vessel position reports within each portion of the channel cross section, Table 2 provides the summary results by month (September and December 2015) for the overall number of towing vessel position reports, number of unique vessels observed, and the relative percentages. 
Table 2. Distribution of towing vessel AIS positions reports within cross section of HSC-S2.

\begin{tabular}{|c|c|c|}
\hline $\begin{array}{l}\text { Portion of HSC } \\
\text { Cross Section }\end{array}$ & $\begin{array}{c}\text { September } 2015 \\
\text { Number of Position Reports } \\
\text { (\% of Total) } \\
\text { Number of Unique Vessels } \\
\text { (\% of Total) }\end{array}$ & $\begin{array}{c}\text { December } 2015 \\
\text { Number of Position Report Counts } \\
\text { (\% of Total) } \\
\text { Number of Unique Vessels } \\
\text { (\% of Total) }\end{array}$ \\
\hline Outbound barge shelf & $\begin{array}{c}90,840(15.0 \%) \\
294(80.1 \%)\end{array}$ & $\begin{array}{c}84,828(14.5 \%) \\
280(80.9 \%)\end{array}$ \\
\hline $\begin{array}{l}\text { Outbound channel side } \\
\text { slope }\end{array}$ & $\begin{array}{c}105,989(17.4 \%) \\
319(86.9 \%)\end{array}$ & $\begin{array}{c}104,399(17.8 \%) \\
305(88.2 \%)\end{array}$ \\
\hline HSC Quarter A & $\begin{array}{c}83,670(13.8 \%) \\
310(84.5 \%)\end{array}$ & $\begin{array}{c}79,808(13.6 \%) \\
305(82.2 \%)\end{array}$ \\
\hline HSC Quarter B & $\begin{array}{c}25,354(4.2 \%) \\
233(63.5 \%)\end{array}$ & $\begin{array}{c}26,284(4.5 \%) \\
218(63.0 \%)\end{array}$ \\
\hline HSC Quarter C & $\begin{array}{c}24,595(4.0 \%) \\
225(61.3 \%)\end{array}$ & $\begin{array}{c}21,531(3.7 \%) \\
217(62.7 \%)\end{array}$ \\
\hline HSC Quarter D & $\begin{array}{c}77,915(12.8 \%) \\
310(84.5 \%)\end{array}$ & $\begin{array}{c}80,533(13.7 \%) \\
294(85.0 \%)\end{array}$ \\
\hline Inbound Channel Side Slope & $\begin{array}{c}103,020(17.0 \%) \\
304(82.8 \%)\end{array}$ & $\begin{array}{c}101,948(17.4 \%) \\
297(85.8 \%)\end{array}$ \\
\hline Inbound Barge Shelf & $\begin{array}{c}96,112(15.8 \%) \\
288(78.5 \%)\end{array}$ & $\begin{array}{c}86,635(14.8 \%) \\
275(79.5 \%)\end{array}$ \\
\hline
\end{tabular}

One point worth noting concerns the seeming imbalance between the percentages of position reports observed in the two middle channel quarters versus the percentage of all unique vessels that are observed in these same quarters at least once during the respective months. Many, if not most, of the towing vessels observed within the HSC are servicing shipping routes that will have them making multiple transits over the course of an entire month, with some vessels making many dozens of trips. Therefore, the unique vessel counts shown in Table 2 simply mean that at least one position report was observed in the respective segment of channel sometime during the respective months, perhaps during only one of many trips made during that time. Therefore, the unique vessel counts should not be interpreted as capturing the percentage of HSC transits that venture into the middle sections; extraction of such quantities would require further spatio-temporal analysis of the AIS position report archive. 
Overall, the spatial analysis of traffic density along the portions of channel cross section shows the highest concentrations of vessel occupancy within the respective side slopes, followed by the designated barge lanes, and then the outer channel quarters. In both months analyzed, only $8.2 \%$ of towing vessel position reports occurred within the two inner quarters of the channel cross section, though over $60 \%$ of towing vessels ventured into those two quarters at least once during each of the respective months. In the broadest, most general terms, towing vessels appear to confine themselves to the designated barge shelves and/or channel side slopes approximately $65 \%$ of the time while venturing into the main deep-draft channel approximately $35 \%$ of the time. 


\section{Results}

\subsection{Houston Ship Channel (HSC) transits by direction and classification of vessel encounter events}

Through use of geo-fenced Areas of Interest (AOI), the AISAP tool used to support this study can quickly and efficiently identify and summarize unique vessel trip counts and direction of travel over defined time periods (USACE-ERDC 2018). AISAP employs a straightforward logic sequence to infer travel times by unique vessels between user-defined AOI by comparing the first and last observed time-stamped position reports within the destination and origin AOI, respectively. While this approach does not ensure that all inferred travel times represent true "straight shot" transits between the origin and destination AOI, the computational efficiency of the approach and the free-form structure of the AISAP work flow provides a flexible capability that is suitable for a wide variety of port and waterway systems. In the case of the HSC, wherein essentially all commercial vessels of interest must remain within the navigation channel, the AISAP approach for inferring vessel transit times is well suited. Figure 4 shows the colorcoded AOIs used within the AISAP application to establish the start and end points for travel time observations of vessels transiting the respective segment of the HSC. In Figure 4 the ends of Segment $\mathrm{S} 1$ are marked by red boxes, Segment $\mathrm{S} 2$ by green boxes, and Segment $\mathrm{S} 3$ by yellow boxes; colors have no significance beyond providing contrast with the underlying satellite image map.

Figure 4. AISAP AOI (color-shaded boxes in $4 a, 4 b$, and $4 c$ indicated by white arrows) used to delineate the ends of straight-line segments of HSC for vessel meeting and overtaking analysis.

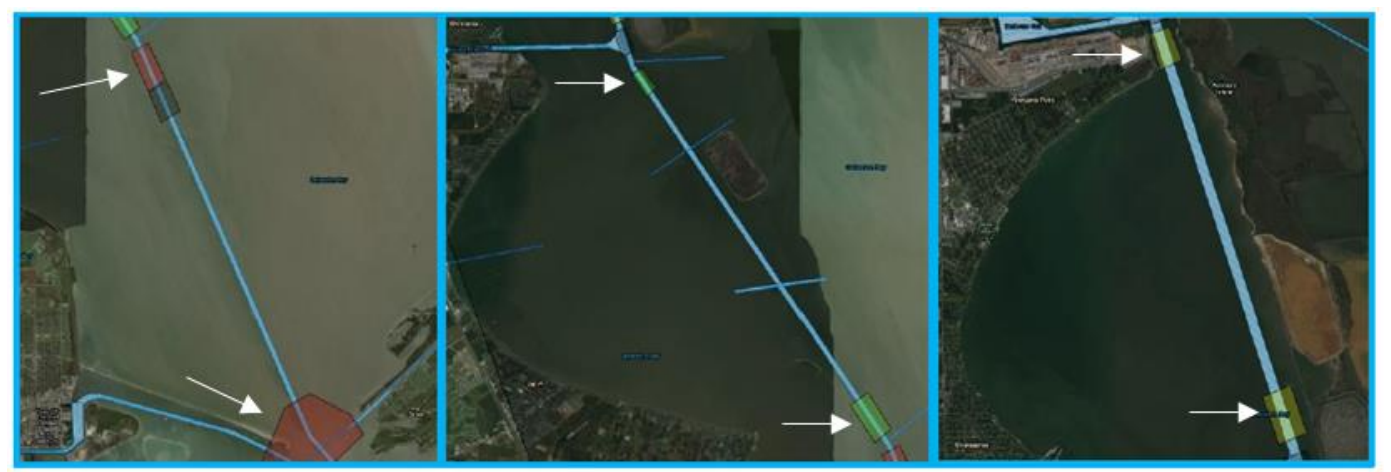

4a) S1, red boxes

4b) S2, green boxes

4c) S3, yellow boxes 
Figure 5 shows a screenshot of the resulting AISAP travel time output. Each row of the output table contains the unique vessel identification information, the label used within the AISAP project to designate the previously occupied AOI, the date-time stamp of the last observed vessel position report within that AOI (column labeled "Leaving"), the label used within the AISAP project for the AOI within which the vessel was next observed, the date-time stamp of the first observed vessel position report within that next AOI (column labeled "Arriving"), the ship and cargo type of the vessel, and the inferred travel time obtained by taking the difference between the respective arrival and departure date-time stamps.

Figure 5. Example of AISAP travel time output file.

\begin{tabular}{|c|c|c|c|c|c|c|c|c|c|}
\hline MMSI & - & Vessel Name & Previous AOI $=$ & Leaving & .1 & $\mathrm{AOI}$ & Arriving & SHIP_AND_CARGO_TYPE - & Travel Time \\
\hline 36743 & & SAINT CHARLES & S2L & $12 / 1 / 2015$ & $8: 18$ & $\mathrm{~S} 2 \mathrm{U}$ & $12 / 1 / 20159: 07$ & 7 Vessel - Towing & $0: 48: 40$ \\
\hline 31937 & & STOLT NORLAND & S2U & $12 / 1 / 2015$ & $8: 52$ & $S 2 \mathrm{~L}$ & $12 / 1 / 20159: 35$ & 5 Tanker - Carrying DG, HS or & $0: 43: 10$ \\
\hline 36699 & & THOR & $S 2 \mathrm{U}$ & $12 / 1 / 2015$ & 9:09 & $S 2 L$ & $12 / 1 / 201510: 19$ & Vessel-Towing & $1: 09: 29$ \\
\hline 22982: & & GALANI & S2L & $12 / 1 / 2015$ & 9:57 & $\mathrm{S} 2 \mathrm{U}$ & $12 / 1 / 201510: 27$ & 7 Cargo Ship - Carrying DG, H & $0: 29: 37$ \\
\hline 30341 & & MAERSK KENTUCKY & S2U & $12 / 1 / 2015$ & 0:00 & $S 2 L$ & $12 / 1 / 201510: 33$ & Cargo Ship - No additional & $0: 32: 44$ \\
\hline 36688 & 150 & MARTIN EXPRESS & S2L & $12 / 1 / 2015$ & 0:08 & $\$ 2 \mathrm{U}$ & $12 / 1 / 201511: 22$ & 2 Vessel - Towing & $1: 13: 48$ \\
\hline 36719 & & POINT ISABEL & S2U & $12 / 1 / 2015$ & $0: 13$ & $S 2 \mathrm{~L}$ & $12 / 1 / 201511: 19$ & Vessel - Towing & 1:06:09 \\
\hline 36764 & & PALACIOS & S2L & $12 / 1 / 2015$ & $0: 14$ & S S2U & 12/1/2015 11:06 & 5 Vessel - Towing & $0: 52: 50$ \\
\hline 31948 & & STOLT EFFICIENCY & S2L & $12 / 1 / 2015$ & $0: 25$ & $\mathrm{~S} 2 \mathrm{U}$ & $12 / 1 / 201510: 59$ & Tanker - Carrying DG, HS or & $0: 34: 20$ \\
\hline 33830 & & MARIYA MORAN & $S 2 \mathrm{U}$ & $12 / 1 / 2015$ & $0: 42$ & $22 \sqrt{3}$ & $12 / 1 / 201511: 23$ & 3 Tanker & $0: 40: 59$ \\
\hline 36697 & & CARISSA B DEVALL & S2U & $12 / 1 / 2015$ & $0: 51$ & $\mathrm{~S} 2 \mathrm{~L}$ & $12 / 1 / 201511: 51$ & 1 Vessel-Towing & $1: 00: 10$ \\
\hline 37382 & 000 & ULTRA ESTERHAZY & S2U & $12 / 1 / 2015$ & $0: 51$ & S2L & $12 / 1 / 201511: 32$ & 2 Cargo Ship & $0: 40: 59$ \\
\hline 36690 & & SKIPJACK & S2L & $12 / 1 / 2015$ & $1: 46$ & $52 \mathrm{U}$ & $12 / 1 / 201512: 48$ & 3 Vessel - Towing (length of & $1: 01: 38$ \\
\hline 36737 & & VICKIE GATES & S2U & $12 / 1 / 2015$ & 2:07 & S2L & $12 / 1 / 201513: 01$ & 1 Vessel - Towing & $0: 54: 48$ \\
\hline 538005 & 261 & ABYSSINIAN & S2U & $12 / 1 / 2015$ & 2:59 & $\mathrm{S} 2 \mathrm{~L}$ & $12 / 1 / 201513: 36$ & 5 Cargo Ship - No additional & $0: 36: 49$ \\
\hline 36747 & & CAPT TOM BROWN & S2U & $12 / 1 / 2015$ & $3: 44$ & S2L & $12 / 1 / 201514: 42$ & 2 Vessel - Towing & $0: 57: 49$ \\
\hline 36616 & & MARYANNHUDSON & S2L & $12 / 1 / 2015$ & 4:03 & $S 2 \mathrm{U}$ & $12 / 1 / 201514: 33$ & 3 Cargo Ship & $0: 30: 19$ \\
\hline 36761 & 880 & TERRY H & S2U & $12 / 1 / 2015$ & 4:11 & $\mathrm{S} 2 \mathrm{~L}$ & $12 / 1 / 201515: 07$ & 7 Vessel-Towing & $0: 56: 20$ \\
\hline 36743 & 050 & STEVEN M BRYAN & S2L & $12 / 1 / 2015$ & $4: 16$ & $52 \mathrm{~S}$ & $12 / 1 / 2015$ 15:26 & 5 Vessel - Towing & $1: 09: 39$ \\
\hline 36748 & & TRIGGER & S2L & $12 / 1 / 2015$ & $4: 36$ & $52 \mathrm{~S}$ & $12 / 1 / 201515: 33$ & 3 Vessel - Towing & $0: 57: 02$ \\
\hline
\end{tabular}

Note that since AOI within AISAP are user-defined, travel time analysis such as this is not limited to origin-destination pair AOI but, in fact, can be extended across an arbitrary number of waterway segments. This capability provides a useful way to quickly extract summary trip data across a continuous range of marine transportation systems (e.g., port-toport movements, localized movements within a port complex, seasonal trends spanning many months). One limitation of this approach that must be understood is that continuous vessel transits are not being directly observed through this process; rather, inferences are made based on the date-time stamps of position reports appearing in the respective AOI. That is to say, there is no direct accounting via this approach for true vessel behavior while traveling between AOI. Furthermore, any potential issues with AIS signal quality and/or coverage gaps between shore-based 
receiving towers can occasionally result in erroneous, excessively long transit time durations. If properly understood, these observations can be filtered out through post-processing without affecting the true statistical distribution governing transit times between the respective AOI. By comparing the entry and exit times of vessels in the respective geo-fenced AOI that define the study segments of the HSC, inferences can be made concerning vessel overtaking events (with vessels moving in the same direction) events as well as meeting events (where vessels are passing in opposite direction), as shown in Figures 6 and 7, respectively.

Figure 6. Visualization of using respective entry/exit time stamps to infer overtaking events.

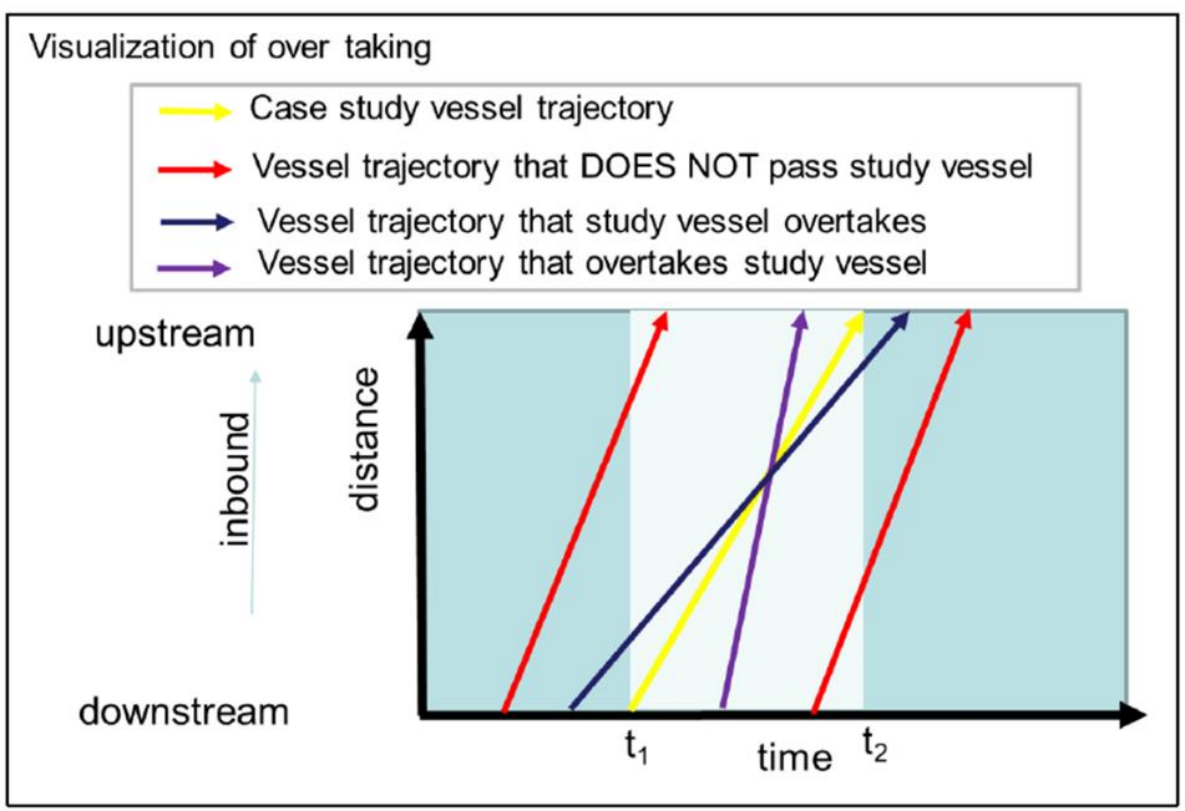

Figure 7. Visualization of using respective entry/exit time stamps to infer meeting events.

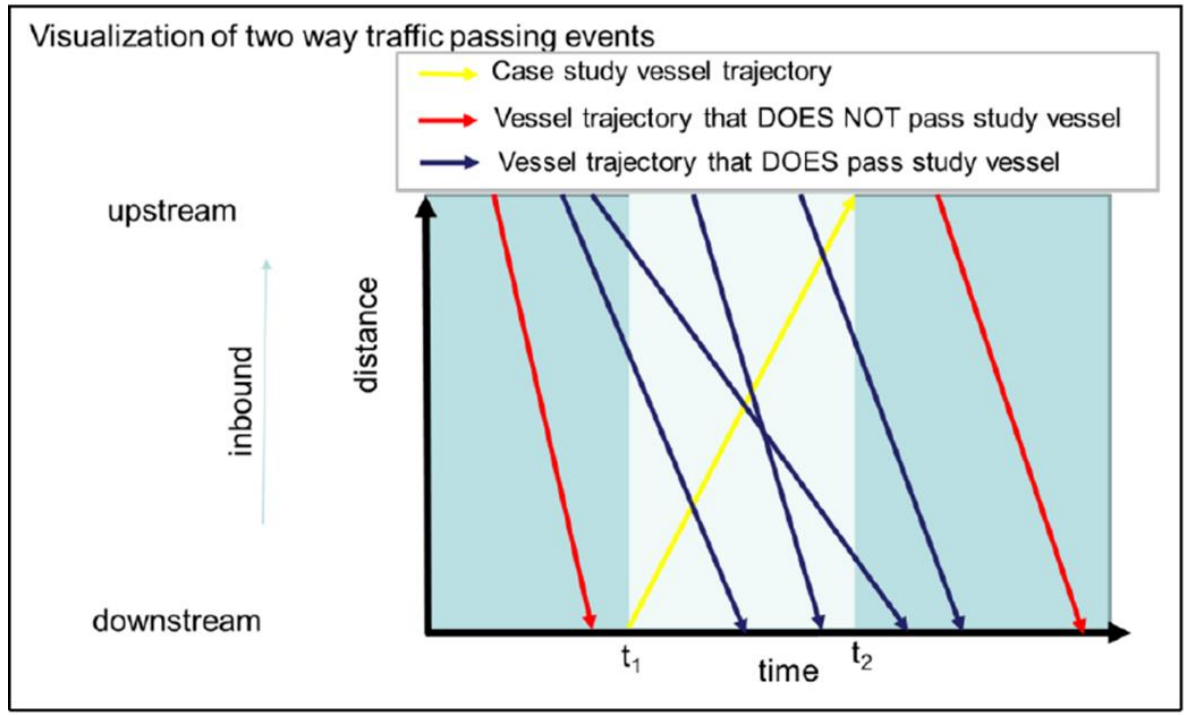


Consider two vessels ( $\mathrm{X}$ and $\mathrm{Y}$ ) traveling in the same direction (i.e., the previous AOI label is the same for each vessel); if vessel $\mathrm{X}$ has the later departure time (based on the leaving time stamp) than vessel $Y$ and vessel $\mathrm{X}$ also has an arrival time in the next AOI before vessel $\mathrm{Y}$, then an overtaking event has taken place while in transit. Likewise, for two vessels (P and Q) transiting in opposite directions, whenever vessel P's departure time from AOI 1 occurs before the arrival time of vessel Q into AOI 1 and vessel P's arrival time in AOI 2 occurs after the departure time of vessel Q from AOI 2, a meeting event during the voyage between AOI 1 and AOI 2 can be inferred.

Identifying information embedded within the AIS messages that are broadcast by the vessels allows for ship types, sizes (beam, length, design draft), and country flag to be used as classifiers for vessel meeting and overtaking events observed within the HSC. To support this study, a custom Excel macro was written to process the AISAP travel time output (Figure 5) and extract the resulting observed summary statistics for that various types of vessel meeting and overtaking events (DiJoseph and Mitchell 2015; DiJoseph et al. 2019). Table 3 provides the number of observations in each segment of the HSC during the month of September 2015.

Table 3. Summary of towing vessels meeting or being overtaken by other vessels (oceangoing or towing), September 2015.

\begin{tabular}{|c|c|c|c|c|c|}
\hline \multirow{2}{*}{ Direction } & \multirow{2}{*}{$\begin{array}{c}\text { HSC } \\
\text { Section }\end{array}$} & \multicolumn{2}{|c|}{ Oceangoing Vessels } & \multicolumn{2}{c|}{ Towing Vessels } \\
\cline { 3 - 6 } & S1 & 1101 & 321 & 1649 & 89 \\
\hline \multirow{2}{*}{$\begin{array}{c}\text { Inbound Towing } \\
\text { Vessels }\end{array}$} & S2 & 1126 & 342 & 1864 & 86 \\
\cline { 2 - 6 } & S3 & 302 & 99 & 490 & 44 \\
\hline \multirow{2}{*}{$\begin{array}{c}\text { Outbound } \\
\text { Towing Vessels }\end{array}$} & S1 & 1027 & 308 & 1649 & 78 \\
\cline { 2 - 6 } & S2 & 1121 & 317 & 1864 & 117 \\
\cline { 2 - 6 } & S3 & 418 & 73 & 490 & 29 \\
\hline
\end{tabular}

For both directions of travel in HSC Segments S1 and S2, there were over 1,000 observed instances of oceangoing bluewater vessels meeting towing vessels traveling in the opposite direction. Owing to its relatively shorter length as well as to some vessels turning into the Bayport Channel, Segment 
S3 saw lower numbers on the order of 300 for inbound vessels and 400 for outbound. For overtaking events, both directions of travel in Segments S1 and S2 saw in excess of 300 instances of bluewater vessels moving ahead of towing vessels traveling in the same direction (overtaking).

Time and funding constraints stemming from the modest scope of DOTS request precluded a similar analysis for December 2015 across all three segments of channel. However, further analysis was conducted for Segment S2 in the month of December, with specific emphasis given to how towing vessel transit times vary as a function of the number of bluewater vessel meeting and overtaking events. For inbound towing vessel transits, there was an average of 1.75 bluewater vessel encounters, with a standard deviation of 1.54. For outbound towing vessel transits, there was an average of 1.81 vessel encounters, with a standard deviation of 1.57. Figures 8 and 9 summarize the relationship between towing vessel transit times and the number of bluewater encounter events for the inbound and outbound directions of travel, respectively.

Figure 8. Inbound towing vessel travel times by number of meeting/overtaking events HSC-S2 - December 2015.

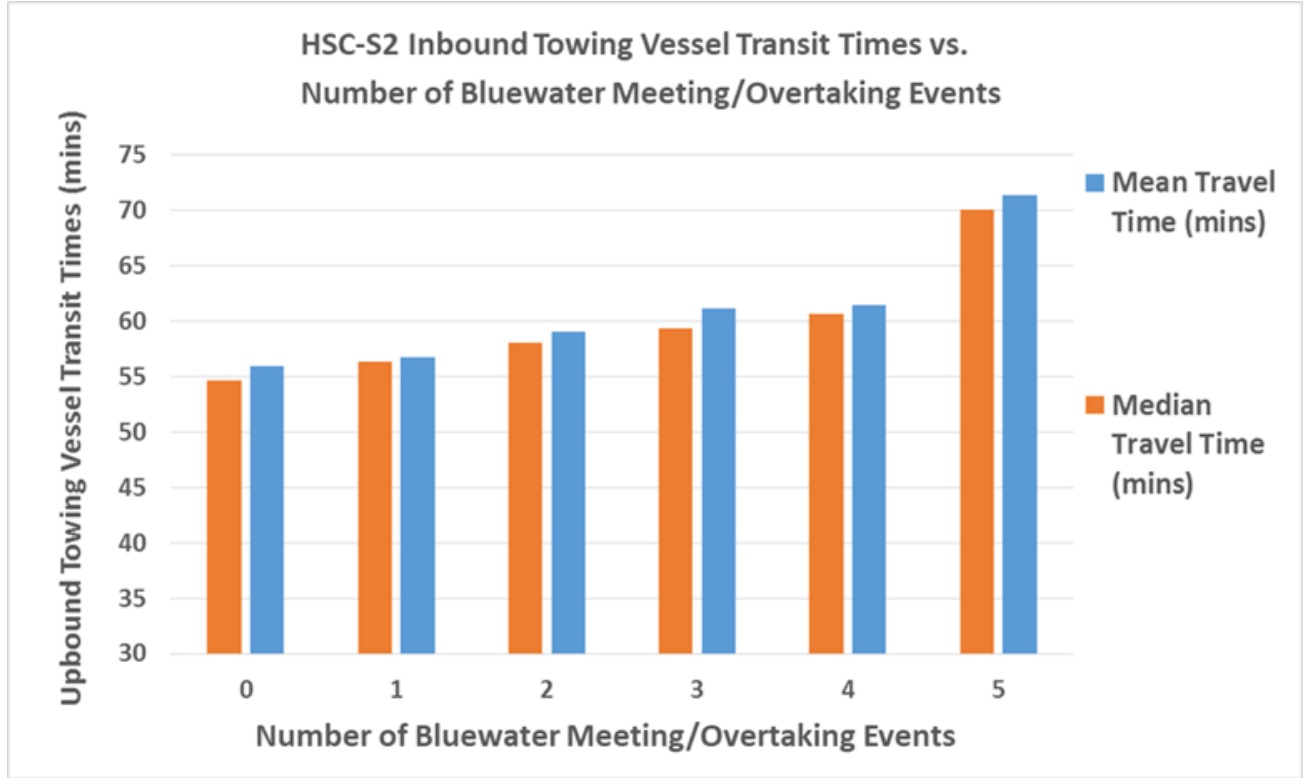


Figure 9. Outbound towing vessel travel times by number of meeting/overtaking events HSC-S2-December 2015.

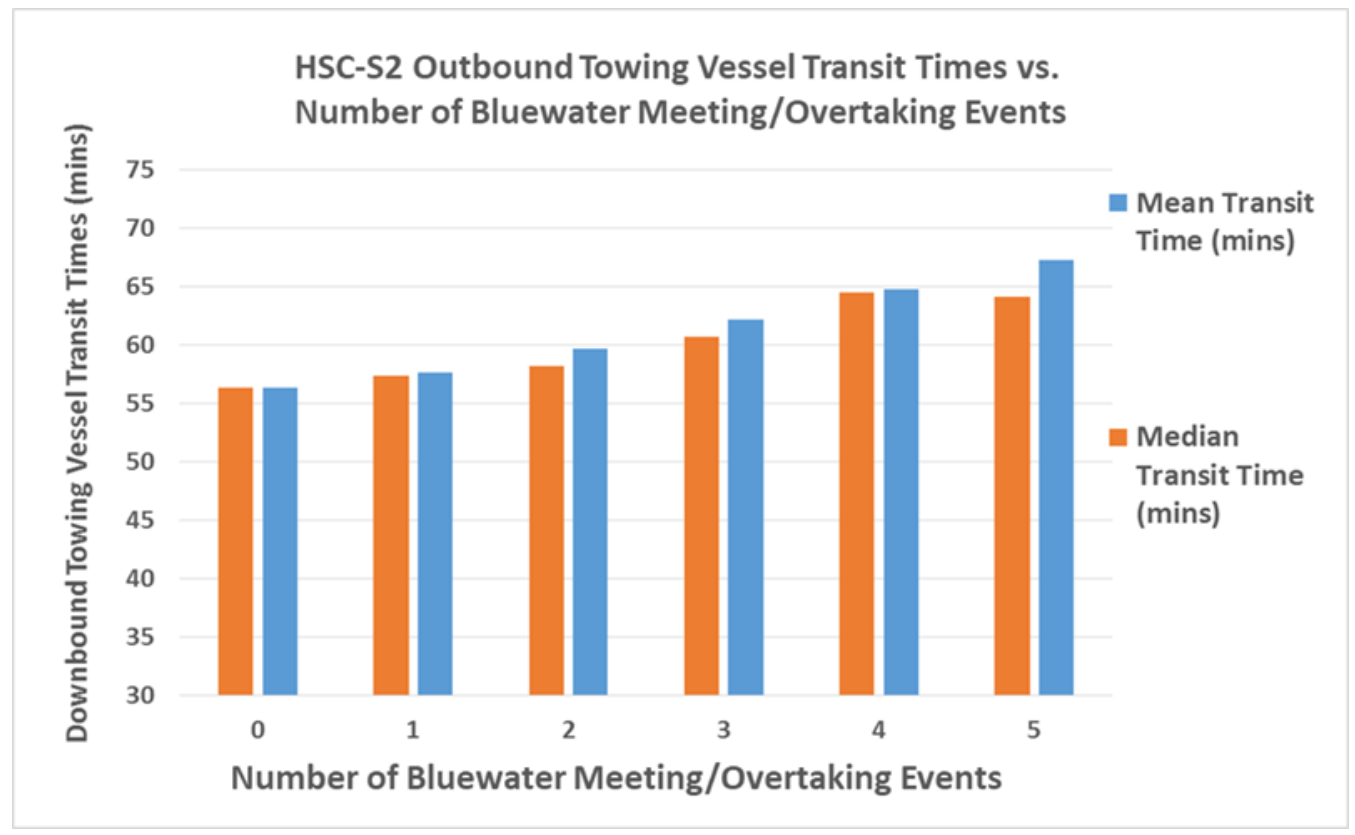

For both directions of travel, there is a clear and consistent trend towards longer transit times for towing vessels as they experience more meeting and/or overtaking events with oceangoing vessels. For inbound towing vessels (Figure 8), the difference between transit times when zero bluewater vessels were encountered versus when five are encountered is approximately 15 minutes ( $\mathrm{min}$ ) (from approximately $55 \mathrm{~min}$ to approximately $70 \mathrm{~min}$ ), an increase of approximately $27 \%$. By comparison, the mean transit time for all inbound towing vessels in Segment S2 was observed to be $58.63 \mathrm{~min}$ in December 2015, and the median value was $57.3 \mathrm{~min}$.

For outbound towing vessels (Figure 9), the observed difference between transit times when zero bluewater vessels were encountered versus when five are encountered is lower than for inbound, less than 10 min in total, but the same clear upward trend is observed. Now, these correlations should not be interpreted as implying causation; it makes intuitive sense that slower moving towing vessels, by virtue of spending more time within Segment S2 of the HSC, are statistically more likely to encounter a larger number of bluewater vessels. Therefore, while these results are interesting and worthy of further study, they stop short of providing a direct linkage between bluewater vessel encounters and drawdown-induced reductions in towing vessel transit speeds. These results also do not consider other 
factors that may influence vessel behavior such as wind, fog, currents, or other operating constraints.

\subsection{Relative linearity of towing vessel tracks as a function of bluewater vessel meeting events}

The final portion of this study sought to relate the number of bluewater vessel encounter events to the degree of linearity observed in towing vessel tracks while transiting Segment S2 of the HSC. Based on descriptions of the drawdown effects experienced by transiting towing vessels in the HSC, it is posited that vessels forced to deviate from an otherwise straight-line heading will appear to have relatively lower $\mathrm{R}^{2}$ coefficients when compared to vessels that do not deviate. In this case, a higher $\mathrm{R}^{2}$ coefficient indicates that the sequentially recorded vessel position reports (latitude and longitude) comprising the vessel track more closely resembles a theoretical straight line running along the channel, which itself is a straight path. This spatial analysis of track line linearity was performed using custom Python scripting that allowed for comparison of vessel position reports to a straight line path, and a resulting $\mathrm{R}^{2}$ coefficient for each unique transit. Dividing the HSC into three separate straight-line segments facilitated this attempt to show a relationship between the number of bluewater vessel encounter events (opposite-direction meeting and same-direction overtaking) experienced by particular towing vessels and the associated degree of linearity of the resulting track. The underlying assumption is that vessels experiencing a higher number of encounter events are more likely to experience potential drawdown effects and/or deviate from a track within the designated barge shelf to avoid possible grounding. Identification of such a relationship would help quantify the true prevalence of the drawdown issues affecting towing vessel traffic within the HSC.

Figure 10 presents two representative towing vessel tracks along with their respective $\mathrm{R}^{2}$ values obtained by comparing each track (made of sequential AIS position reports) to a straight line running the length of Segment S2. Though both tracks are shown to be almost perfectly linear when analyzed across the full length (approximately 7.75 miles) of Segment S2, the track with the lower $\mathrm{R}^{2}$ value displays a visibly noticeable tendency to veer across multiple portions of the HSC cross section. The same tendency is evident when looking at multiple transits by multiple towing vessels. 
Figure 10. Comparison of towing vessel tracks with "high" $\mathrm{R}^{2}$ value (green line) and relatively “low" $\mathrm{R}^{2}$ value (purple line).

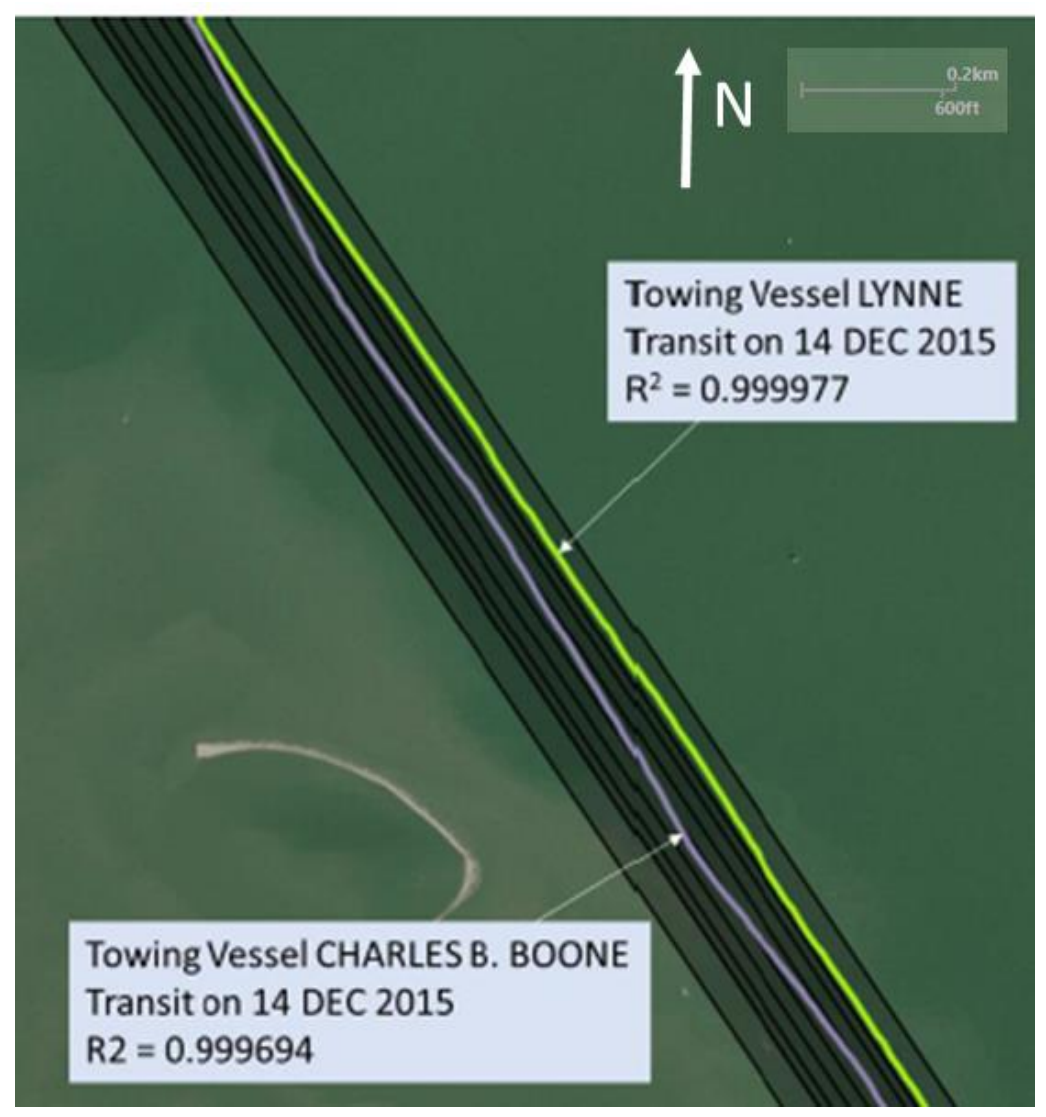

Figures 11 and 12 show comparisons between tracks with relatively high $\mathrm{R}^{2}$ values ( $>=.999975)$ and those with relatively low $\mathrm{R}^{2}$ values (<.999845) for two different locations within HSC Segment S2. In both cases, the high R ${ }^{2}$ tracks appear to be more tightly clustered together while the lower $\mathrm{R}^{2}$ tracks show more of a tendency to meander across portions of the channel cross section. As such, use of the $\mathrm{R}^{2}$ coefficient would appear to be a useful way to quantify the relative degree of linear consistency of transiting vessels within straight portions of maintained navigation channels, thereby providing a consistent and repeatable approach for processing many hundreds of transits. 
Figure 11. Comparison of towing vessel tracks with relatively high $R^{2}$ (panel $A$ ) and low $R^{2}$ (panel B) coefficients within a southern portion of HSC-S2.
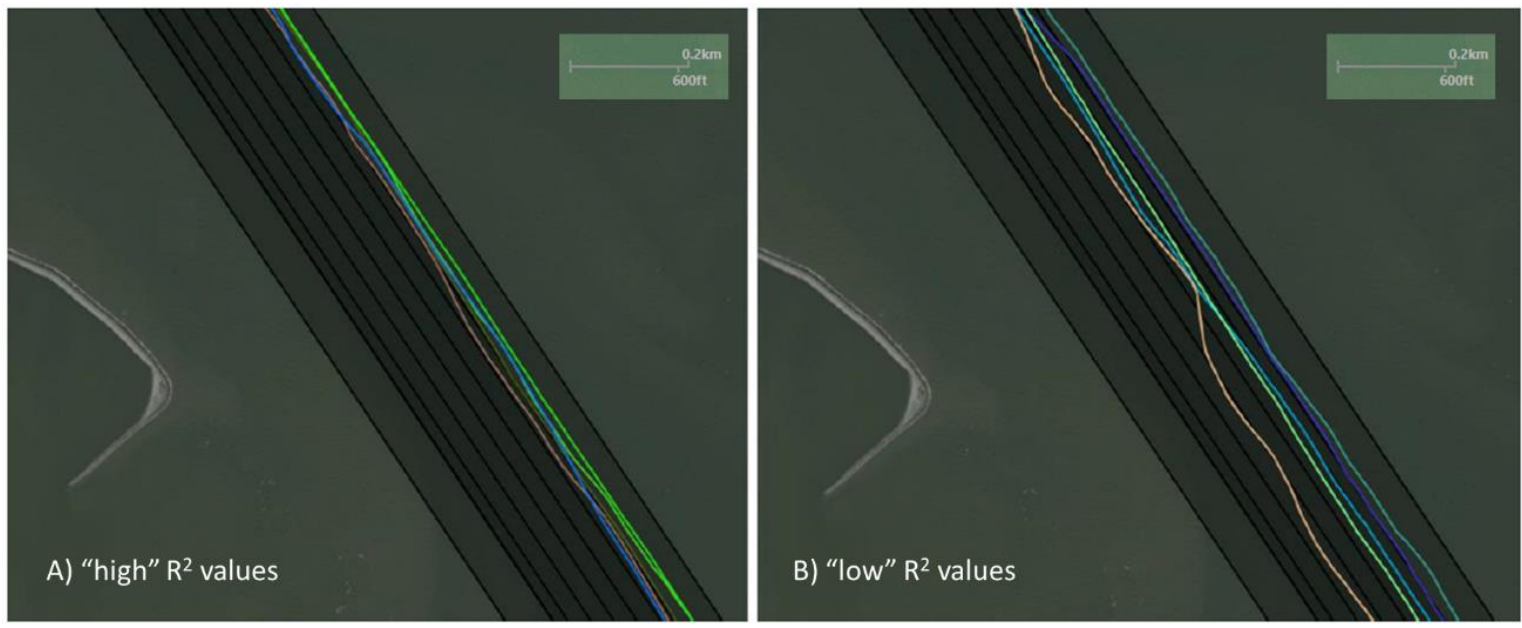

Figure 12. Comparison of towing vessel tracks with relatively high $R^{2}$ (panel $A$ ) and low $R^{2}$ (panel B) coefficients within a northern portion of HSC-S2.
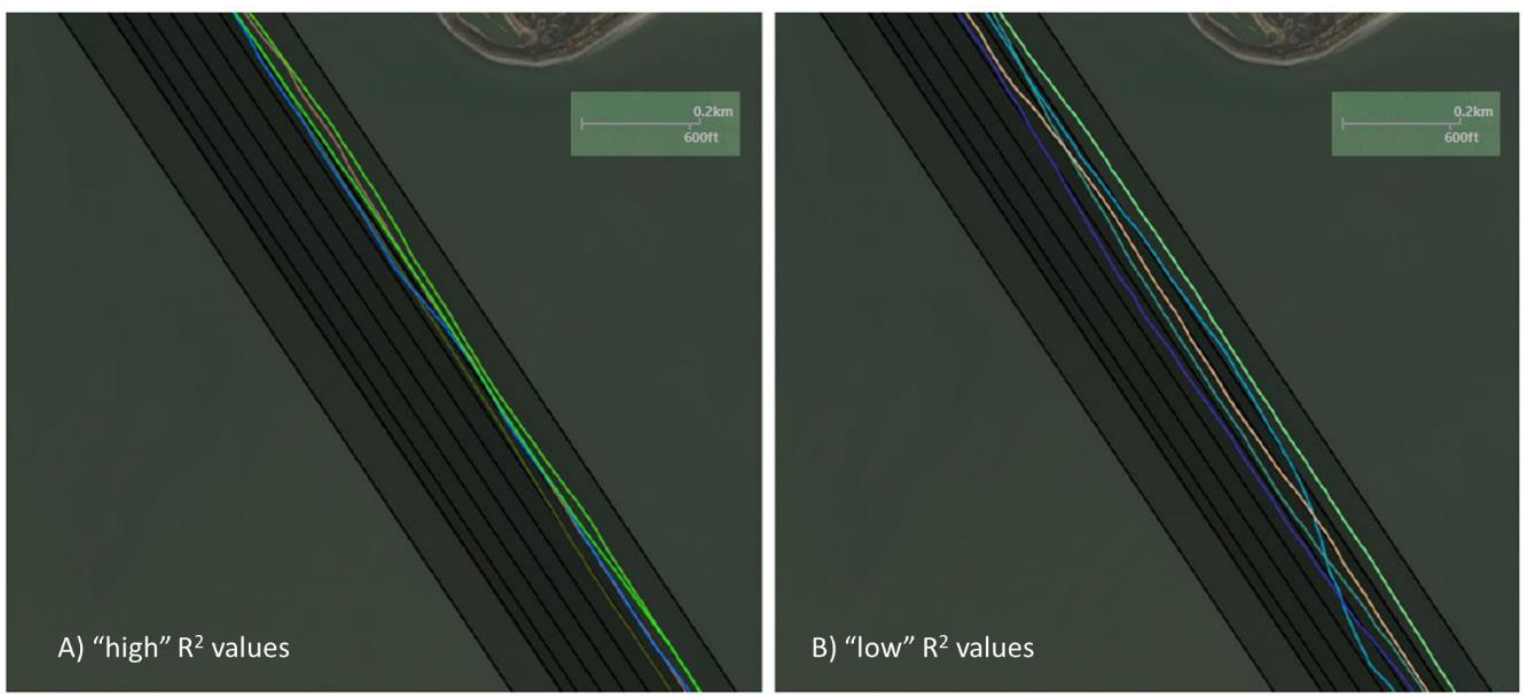

As in the previous section of this report, the number of bluewater vessel meeting/overtaking events was used as a classifier to determine what trends, if any, could be observed with the $\mathrm{R}^{2}$ coefficients of the corresponding towing vessel tracks. A custom script was written to match the calculated $\mathrm{R}^{2}$ coefficients with the unique vessels making the transit, along with associated departure/arrival times within the various AOI defined within the AISAP project used to support this study. Due to the time and funding constraints of the DOTS study, only results from December 2015 for inbound towing vessel transiting Segment $\mathrm{S} 2$ were fully analyzed. Figure 13 summarizes the main findings from this analysis. Though far from conclusive, there are some interesting aspects that underscore the 
need for a more thorough, comprehensive treatment of the potential drawdown issues in the HSC via AIS archival data.

Figure 13. Trends in towing vessel track $R^{2}$ values as bluewater vessel encounters increase HSC-S2- December 2015.

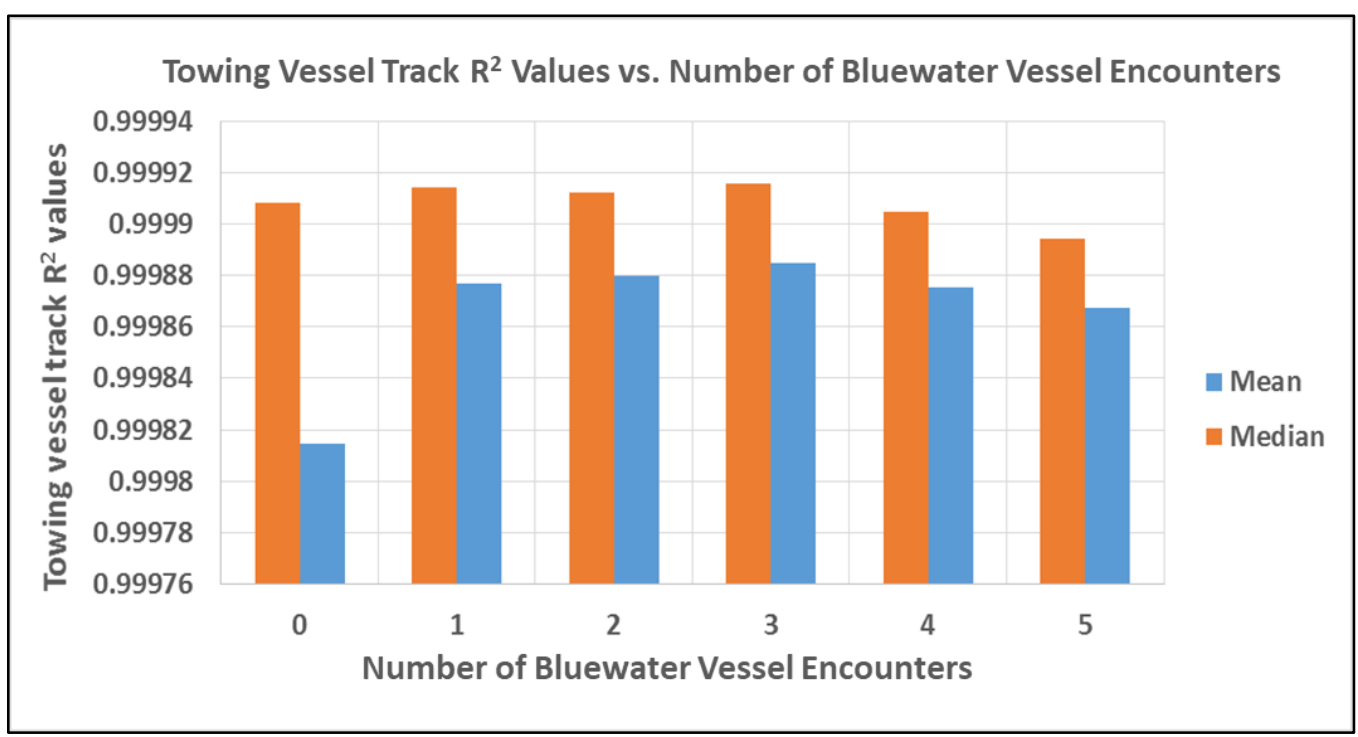

The mean and median $\mathrm{R}^{2}$ values are shown for each group of towing vessels based on the number of bluewater vessel encounter events. Median values are less sensitive to influence from a relative few outlier values, thereby providing a more consistent value for comparison. Though admittedly speculative, it is at least possible that the relatively low mean $\mathrm{R}^{2}$ values observed for towing vessels experiencing zero bluewater encounter events can be attributed to a "free rein" effect. Without any bluewater vessels to contend with, towing vessel pilots are largely free to transit within whichever portion of HSC cross section they favor. At any rate, the median values as well as the mean (other than the afore-mentioned case of zero bluewater vessel encounters) $\mathrm{R}^{2}$ coefficients generally hold steady up to three bluewater encounter events, after which there is a noticeable drop-off for both statistical metrics. Figure 14 presents the same data as shown in Figure 13, but with mean values removed and a smaller vertical axis scale to more clearly show the difference in $\mathrm{R}^{2}$ coefficients as the number of bluewater vessel encounters increases. 
Figure 14. Median $\mathrm{R}^{2}$ values for towing vessel tracks as bluewater vessel encounters increase, HSC-S2, December 2015.

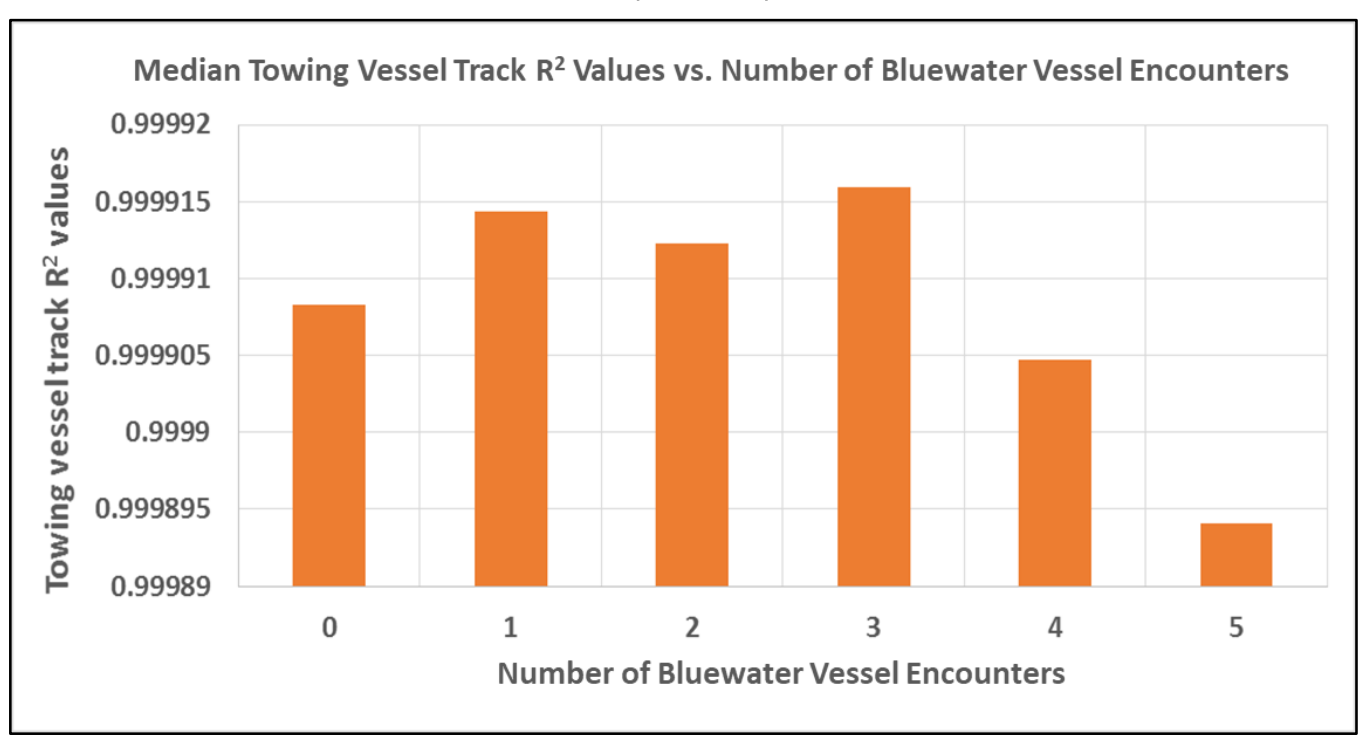

Presented thus, there would appear to be some, albeit limited, quantitative evidence that towing vessels encountering at least four bluewater vessels (in Segment S2 of the HSC, as defined in this study) experience an observable reduction in the degree of track linearity, implying that drawdown effects and/or conscious efforts to steer into the deeper side slope and deep-draft portions of the main channel are prevalent. 


\section{Summary and Conclusions}

This DOTS-funded study has demonstrated several potential avenues for further detailed and comprehensive analysis of marine vessel traffic patterns within federally maintained navigation channels, all made possible with the advent of archival AIS position report data. The USACEERDC AISAP software (https://ais-portal.usace.army.mil) provides an enabling capability for quickly procuring and processing the large amounts of spatio-temporal data required to draw meaningful conclusions concerning complex problems such as that seen with drawdown effects in the HSC. An AISAP spatial analysis showed that towing vessels venture into the main deep-draft HSC approximately 35\% of the time. The AISAP transit time capability used in tandem with custom analysis Python scripting has been shown to be a useful way to tabulate meeting and overtaking events between towing and oceangoing vessels. Clear increasing trends were observed between the transit times of towing vessels in one middle segment of the HSC (Segment S2 in this study) and the corresponding number of bluewater vessel encounter events. Finally, an attempt was made to use the $\mathrm{R}^{2}$ coefficient of towing vessel tracks relative to a linear ideal to further determine the extent to which bluewater vessel meeting/overtaking events cause disruptions for towing vessel transits. Though far from conclusive, the analysis shows that towing vessels experiencing relatively high numbers of bluewater vessel encounters display a noticeable tendency towards lower mean and median R2 values (i.e., less linearity in the overall track signature).

Further analysis across larger temporal domains, and perhaps across other spatial extents within the HSC navigation project footprint, will be necessary to definitely prove or disprove the prevalence of oceangoing vessel-induced drawdown impacts to towing vessel operations. Archival AIS data are shown here to be a cost-effective way to quantify traffic density trends across time and space, and to begin to understand and isolate instances where navigation channel design deficiencies combined with prevailing traffic patterns are leading to unsafe and/or sub-optimal operational efficiencies for transiting vessels. This adds to a growing body of work utilizing AIS data for revealing patterns of navigation channel infrastructure use (DiJoseph and Mitchell 2015; DiJoseph et al. 2019; Mitchell and Scully 2014; Scully and Mitchell 2015). 


\section{References}

DiJoseph, P. K., and K. N. Mitchell. 2015. "Estimating Vessel Travel Time Statistics for Inland Waterways with Automatic Identification System Data.” Transportation Research Board Annual Meeting Compendium of Papers. Washington, DC: Transportation Research Board.

Dijoseph, P. K., K. N. Mitchell, B. J. Tetreault, and J. Marshall. 2019. Inland Marine Transportation System Travel Time Atlas via Automatic Identification System (AIS) Data: Ohio River, Upper Mississippi River, and Illinois River. ERDC/CHL TR-19-15. Vicksburg, MS: U.S. Army Engineer Research and Development Center. http://chl.erdc.usace.army.mil

Mitchell, K. N., and B. N. Scully. 2014. "Waterway Performance Monitoring via Automatic Identification System (AIS) Data." Transportation Research Record: Journal of Transportation 2426(1): 20-26.

Scully, B., and K. N. Mitchell. 2015. Archival Automatic Identification System (AIS) Data for Navigation Project Performance Evaluation. ERDC/CHL CHETN-IX-40. Vicksburg, MS: U.S. Army Engineer Research and Development Center. http://chl.erdc.usace.army.mil/chetn

USACE-ERDC (U.S. Army Corps of Engineers, U.S. Army Engineer Research and Development Center). 2018. AIS Analysis Package (AISAP). Software package. https://ais-portal.usace.army.mil

U.S. Coast Guard. 2018. Navigation Center. "Automatic Identification System Overview." http://www.navcen.uscg.gov/?pageName=AISmain 


\section{Unit Conversion Factors}

\begin{tabular}{|l|c|l|}
\hline Multiply & By & To Obtain \\
\hline degrees (angle) & 0.01745329 & radians \\
\hline feet & 0.3048 & meters \\
\hline miles (nautical) & 1,852 & meters \\
\hline miles (US statute) & $1,609.347$ & meters \\
\hline miles per hour & 0.44704 & meters per second \\
\hline
\end{tabular}




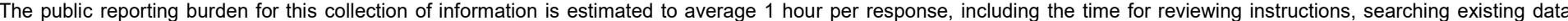

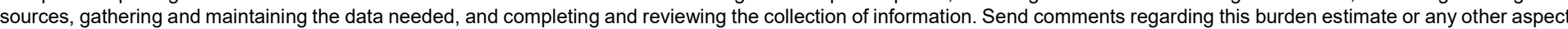

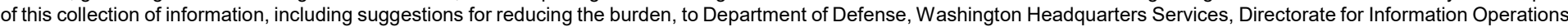

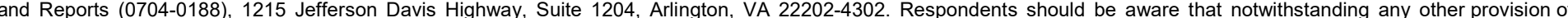
law, no person shall be subject to any penalty for failing to comply with a collection of information if it does not display a currently valid OMB control number.

PLEASE DO NOT RETURN YOUR FORM TO THE ABOVE ADDRESS.

\begin{tabular}{l|l|l}
\hline $\begin{array}{l}\text { 1. REPORT DATE } \\
\text { January } 2020\end{array}$ & $\begin{array}{l}\text { 2. REPORT TYPE } \\
\text { Final Report }\end{array}$ & 3. DATES COVERED (From - To)
\end{tabular}

\section{TITLE AND SUBTITLE}

Final Report

Towing Vessel Delays and Barge Lane Navigability along the Houston Ship Channel, Texas

5a. CONTRACT NUMBER

5b. GRANT NUMBER

5c. PROGRAM ELEMENT NUMBER

6. AUTHOR(S)

Kenneth N. Mitchell, Patricia K. DiJoseph, Brandan M. Scully, and Marin M. Kress

5d. PROJECT NUMBER

468419

5e. TASK NUMBER

5f. WORK UNIT NUMBER

8. PERFORMING

ORGANIZATION REPORT

NUMBER

ERDC/CHL TR-20-1

U.S. Army Engineer Research and Development Center

3909 halls Ferry Road

Vicksburg, MS 39180-6199

9. SPONSORING/MONITORING AGENCY NAME(S) AND ADDRESS(ES)

U.S. Army Corps of Engineers, Galveston District

10. SPONSOR/MONITOR'S ACRONYM(S)

USACE SWG

2000 Fort Point Rd.

Galveston, TX 77550

11. SPONSOR/MONITOR'S

REPORT NUMBER(S)

\section{DISTRIBUTION/AVAILABILITY STATEMENT}

Approved for public release; distribution is unlimited.

\section{SUPPLEMENTARY NOTES}

\section{ABSTRACT}

This project used historic vessel position reports to analyze barge lane traffic navigability and towing vessel traffic interaction with deep draft ("bluewater") vessels in the Houston Ship Channel, Texas, during September and December 2015. Vessel position reports were collected through the U.S. Coast Guard Nationwide Automatic Identification System (AIS) and accessed through the U.S. Army Corps of Engineers AIS Analysis Package software. The motivation for this study was a request from the Galveston District for assistance as part of the Houston Ship Channel Expansion Channel Improvement Project. Results indicate that, generally, towing vessels confine themselves to the designated barge shelves on the outer edges of the main channel approximately $65 \%$ of the time and venture into the main (center) portion of the deep-draft channel approximately $35 \%$ of the time. This study also explored the relationship between meeting events (where a bluewater vessel is meeting a towing vessel moving in the opposite direction) and the linear consistency of towing vessel tracks within the barge lanes along straight segments of the Houston Ship Channel. Preliminary results suggest that encounter events do influence towing vessel behavior, as measured through vessel track linearity.

\section{SUBJECT TERMS}

Barges, Channels (Hydraulic engineering), Houston Ship Channel (Tex.), Inland navigation, Ships, Towing

\section{SECURITY CLASSIFICATION OF:}

\begin{tabular}{|l|c|l|}
\hline a. REPORT & b. ABSTRACT & c. THIS PAGE \\
Unclassified & Unclassified & Unclassified \\
& & \\
\hline
\end{tabular}

17. LIMITATION OF ABSTRACT

SAR
18. NUMBER 19a. NAME OF RESPONSIBLE PERSON

OF
PAGES

30
Kenneth N. Mitchell

19b. TELEPHONE NUMBER (Include area code)

$601-529-9005$ 